\title{
Effects of altitude, ambient temperature and solar radiation on fasting heat production in yellow cattle (Bos taurus)
}

\author{
Xing-Tai Han*, Ao-Yun Xie, Xi-Chao Bi, Shu-Jie Liu and Ling-Hao Hu \\ Institute of Animal Science, Qinghai Academy of Animal and Veterinary Sciences, 810003, Xining, Qinghai, China
}

(Received 14 November 2001 - Revised 30 September 2002 - Accepted 15 October 2002)

\begin{abstract}
Growing yellow cattle (Bos taurus, $n$ 30, 1.0-3.5 years old and 75-240 kg) from their native altitude (2000-2800 m) were used to evaluate the effects of altitude, ambient temperature (Ta) and solar radiation on the basal energy metabolism in this large mammal. Fasting heat production (FHP) was measured at altitudes of 2260,3250 and $4270 \mathrm{~m}$ on the Tibetan plateau both in the summer and winter respectively, after a $90 \mathrm{~d}$ adaptation period at each experimental site. The gas exchanges of the whole animal were determined continuously for 3 (2260 and $3250 \mathrm{~m})$ or $2(4270 \mathrm{~m}) \mathrm{d}$ after a $96(2260$ and $3250 \mathrm{~m})$ or $48(4270 \mathrm{~m}) \mathrm{h}$ starvation period, using closed-circuit respiratory masks. Increasing altitude from 2260 to $3250 \mathrm{~m}$ at similar Ta in the summer significantly elevated FHP for all animals $(P<0 \cdot 01)$, and from 3250 to $4270 \mathrm{~m}$ for young cattle $(P<0 \cdot 05)$; increasing altitude from 2260 to $3250 \mathrm{~m}$ in the winter also significantly elevated FHP $(P<0.05)$, but the increase was mainly due to the decrease of Ta and the increase in wind speed. No results were obtained at $4270 \mathrm{~m}$ in the winter, due to the problems of the animals, adaptating to the altitude. The magnitude of FHP elevation caused by increasing altitude was greater with summer sunshine or winter wind than without them. Increase of Ta from 10.0 to $22.0^{\circ} \mathrm{C}$, in the presence of solar radiation, slightly $(2260 \mathrm{~m})$ or significantly $(3250$ and $4270 \mathrm{~m}, P<0.01)$ elevated FHP, but slightly reduced it in the absence of solar radiation; decrease of Ta from $0 \cdot 0$ to $-30 \cdot 0^{\circ} \mathrm{C}$ linearly increased FHP. At 3250 and $4270 \mathrm{~m}$, FHP at the same Ta was higher with summer sunshine or winter wind $(3250 \mathrm{~m})$ than without them, but this did not occur at $2260 \mathrm{~m}$. In conclusion, high altitude elevates FHP in yellow cattle in the warm season, and the summer solar radiation and winter wind at high altitude significantly increase metabolic rate. It may be also concluded that the effects of solar radiation on metabolic rate depend on the altitude and the environmental temperature.
\end{abstract}

Altitude: Ambient temperature: Solar radiation: Fasting heat production: Cattle

The energy expenditure of animals is profoundly influenced by characteristics of the physical environment such as altitude, ambient temperature (Ta), solar radiation and wind speed. The effects of Ta in various domestic animals have been well documented (National Research Council, 1981). The metabolic and respiratory responses of animals and human subjects to high altitude has also received greater attention, and the $\mathrm{O}_{2}$ concentration in the air clearly plays a significant role in determining the metabolic rate, especially in small species (for review, see Gautier, 1996). Solar radiation represents a potentially overwhelming heat load to animals and may therefore have an important influence on their thermoregulatory metabolism and heat balance, especially in grazing animals. Several studies have determined the effect of direct solar radiation on thermoregulatory responses in a hot environment in cattle; however, only a few have focused on the influence of solar radiation on heat energy expenditure under different thermal conditions (Yamamoto et al. 1994; Brosh et al. 1998), and none has been conducted at moderate or high altitude.

At high altitude, the environment is characterised by a lower $P_{\mathrm{O}_{2}}$, a lower temperature and a stronger solar radiation than low altitude environments at similar latitudes. The lower $P_{\mathrm{O}_{2}}$ may reduce the $\mathrm{O}_{2}$ consumption in small animals, but the colder temperature, on the other hand, may increase it by increasing thermogenesis (for review, see Gautier, 1996). These responses, in turn, may be modified by the stronger solar radiation through its greater heat load. To our knowledge, the effects of such a complicated 
environment on metabolic rate remain unclear. We hypothesised that there might be some interactions between altitude, Ta and solar radiation, and that the energy budgets of animal or human subjects at high altitude therefore are not only affected by a single factor, but also by combinations of these climatic variables.

The objectives of the present study were to investigate the responses of metabolic rate in large mammals to high altitude, Ta, the summer solar radiation and the winter wind, and to the possible interactions among these factors, by measuring fasting heat production (FHP) in 30 yellow cattle (Bos taurus) at 2260, 3250 and $4270 \mathrm{~m}$ both in the summer and winter, using closed-circuit respiratory masks.

\section{Materials and methods}

\section{Experimental sites, animals and management}

The experiments were conducted both in cold and warm seasons on the Qinghai-Tibet plateau in western China. The experimental sites selected were Qinghai Academy of Animal and Veterinary Sciences (lat $36^{\circ} 37^{\prime} \mathrm{N}$, long $101^{\circ} 46^{\prime} \mathrm{E}$ ), Tiepujia Pasture Improvement Station (lat $37^{\circ} 05^{\prime} \mathrm{N}$, long $99^{\circ} 35^{\prime} \mathrm{E}$ ) and Maduo Veterinary Station (lat $34^{\circ} 55^{\prime} \mathrm{N}$, long $98^{\circ} 13^{\prime} \mathrm{E}$ ). The Academy is in an agriculture area, and the two stations are located on the typical alpine meadow. The altitudes at these sites are 2260, 3250 and $4270 \mathrm{~m}$, and the measured air pressures are $576.8 \pm 2 \cdot 8$, $514.9 \pm 3.3$ and $454.5 \pm 3.3 \mathrm{mmHg}$ respectively. The mean air temperatures recorded in the last decade in these sites are 17.2 (range 10.0-28.0), 10.5 (range 2.0-21.0) and 7.5 (range $-1.0-19.0)^{\circ} \mathrm{C}$ in July, and -7.7 (range $-19 \cdot 0-0.0$ ), -15.2 (range $-5.0--27 \cdot 0$ ) and -16.8 (range $\left.-7 \cdot 0_{-}-30\right)^{\circ} \mathrm{C}$ in January respectively. There is no absolute frost-free period during any part of the year at 3250 and $4270 \mathrm{~m}$.

Growing yellow cattle ( $n$ 30), aged $1.0-3.5$ years and body weight (BW) $75-240 \mathrm{~kg}$ (mature BW for the females ranged from 280 to $320 \mathrm{~kg}$ ), were used. They were collected from their native areas in the eastern part of the Qinghai-Tibet plateau, where the altitude ranges from 2000 to $2800 \mathrm{~m}$. The animals are mostly covered by a coat of yellow hair, which is relatively thicker, fleecier and denser than that in other breeds such as the dairy cow. The cattle were divided, in later measurements, into three groups (four animals per group) according to their ages $(1 \cdot 0-1.5,2 \cdot 0-2.5$ and $3 \cdot 0-3.5$ years). The experiments lasted for 3 years, and so those cattle that were $>3.5$ years were culled and new young animals were selected again to maintain the designed age and BW in each group. The selected cattle were first transported to the stalls at Qinghai Academy of Animal and Veterinary Sciences, where they received a 3-month training programme for various measurements. During the training period, respiratory masks were given to the animals every morning and afternoon ( $30 \mathrm{~min}$ each time); the measurements for respiratory rate, heart rate and rectal temperature were practiced every morning and every week for BW.

The cattle at $2260 \mathrm{~m}$ were housed in a half-open house with access to outside, or kept in a fence without any shelter at altitudes 3250 and $4270 \mathrm{~m}$. Animal housing at $2260 \mathrm{~m}$ was similar before and during measurements, except for an outside tethering during measurements. At $2260 \mathrm{~m}$, the animals were fed, during the training and non-measurement period, a straw-concentrate diet at twice maintenance level (National Research Council, 1984); at altitudes of 3250 and $4270 \mathrm{~m}$, the animals were allowed to graze during the day, and the supplemental feed was given in the evening in the cold season.

\section{Measurements}

The measurements, which lasted for 3 years, commenced at the altitude $2260 \mathrm{~m}$ and ended at the altitude $4270 \mathrm{~m}$, 1.0 year for each altitude site. The animals were taken to each new experiment site in March every year, and the measurements were carried out in July or August (June at $2260 \mathrm{~m}$ ) for summer data, and in December or January for winter data.

At each experimental site, twelve animals, four per age group, were used. The animals were deprived of feed or grazing, but not of water, for $7 \mathrm{~d}$ at 2260 and $3250 \mathrm{~m}$, and for $4 \mathrm{~d}$ at $4270 \mathrm{~m}$. BW was measured in the morning of day 5 and $8(2260$ and $3250 \mathrm{~m})$ or day 3 and 5 $(4270 \mathrm{~m})$ of starvation; respiratory rate, heart rate and rectal temperature were measured every morning during the starvation. The respiratory rate and heart rate were measured by counting the rate of flank movement and heart beat for $3 \mathrm{~min}$, using a stethoscope for the latter; the rectal temperature was measured with thermometer after $4 \mathrm{~min}$ in the rectum. Gas exchanges for the whole animal were collected for $3(2260$ and $3250 \mathrm{~m})$ or 2 $(4270 \mathrm{~m}) \mathrm{d}$ consecutively begun from day 5 (2260 and $3250 \mathrm{~m})$ or day $3(4270 \mathrm{~m})$; closed-circuit respiratory masks were connected, with two gas-tight pipes (internal diameter $50 \mathrm{~mm}$ ), to a gas-tight rubber box with a volume of $2 \mathrm{~m}^{3}$ and an exit for sample collection. The mask was separately equipped with two movable valves at the connection points with gas-tight pipes, one for inspiration and the other for expiration. The connection pipe was $2-3 \mathrm{~m}$ long and equipped with a valve either to the outside air or to the air in the box. Before each measurement, the mask was given to the animal with the pipe valve opening to the air for several minutes; the valve was then turned to the box for measurement. In the summer, the gas collection was performed at 09.00, $15.00,22.00$ and 04.00 hours for $10-12 \mathrm{~min}$ each time. These measurements represented gas exchanges during $08.01-11.00,11.01-20.00,20.01-24.00$ and $0.01-08.00$ hours respectively. The gas-collection frame in the winter was essentially the same as in the summer, except for an additional collection at 18.00 hours representing 16.0120.00 hours. The time zones were mainly based on changes of Ta recorded continuously for 1 week before gas collection. The recorded $\mathrm{Ta}$ in each zone was averaged at the gas-collection hour and appeared relatively stable within the time zone.

Immediately after gas collection, the gas in the collection box was homogenised and a gas sample was taken into a small gas-tight bag for analysis. The total volume of the gas in the collection box was then recorded by 
withdrawing the gas with hygrometric gas-flow meter connected to gas pump. $\mathrm{O}_{2}$ and $\mathrm{CO}_{2}$ concentrations in both the collected gas and the air were analysed within 20 min after collection (Han et al. 2002).

During the gas-collection days, the standing time of the animals in each time zone was recorded continuously. Temperature, pressure and relative humidity in both the air and the gas-collection boxes were recorded at each collection time. The presence of sunshine in the summer and the wind speed in the winter at the collection time were also recorded.

\section{Calculations and statistics}

Fasting BW over each measurement period was calculated as the mean of the BW measured on days 5 and 8 (2260 and $3250 \mathrm{~m})$ or days 3 and $5(4270 \mathrm{~m})$ of starvation. The gas volume in the collection box was converted into the volume of standard gas, using the equation $\mathrm{V}_{0} \mathrm{P}_{0} / \mathrm{T}_{0}=$ $\mathrm{V}_{1} \mathrm{P}_{1} / \mathrm{T}_{1}$, where $\mathrm{V}_{0}, \mathrm{P}_{0}$ and $\mathrm{T}_{0}$ represent gas volume, air pressure $(760 \mathrm{mmHg})$ and temperature $\left(0^{\circ} \mathrm{C}\right)$ under standard conditions, and $\mathrm{V}_{1}, \mathrm{P}_{1}$ and $\mathrm{T}_{1}$ represent measured gas volume, air pressure and temperature respectively. In the calculation, the variations of air relative humidity in the gas-collection box were also taken into account. FHP, based on the gas volume under standard conditions, was calculated according to the formula of Brouwer (1965). The total FHP in each time zone was calculated as the product of $\mathrm{FHP} / \mathrm{h}$ and the total number of hours in the zone, and then corrected into FHP under real standing-lying conditions according to the animal's standing time, assuming that the heat production is $15 \%$ higher in the standing than in the lying situation (Han, 1990). The total daily FHP of each animal was calculated as the sum of heat production from all time zones throughout the $24 \mathrm{~h}$. The data obtained at 09.00 and 15.00 hours with two higher age groups (the FHP was higher for young cattle and was therefore excluded) were classified into different groups to clarify the effects of altitude, Ta, summer solar radiation and winter wind. The RER is defined as the $\mathrm{CO}_{2}$ production: $\mathrm{O}_{2}$ consumption ratio.

Data were analysed, first by ANOVA with animal, age group and altitude, with mean values per animal and per altitude as the experimental unit. The classified data were also analysed by ANOVA with mean values per altitude, Ta, summer radiation and winter wind as units. Differences between the winter and summer for the same group at the same altitude were analysed by $t$ test. The data pooled from the four to five measurements throughout the $24 \mathrm{~h}$ were finally treated by ANOVA for altitude and season effects and their interactions. Variables were considered unaffected by altitude, Ta, solar radiation and wind or not significantly different between groups if $P>0.05$.

\section{Results}

\section{Animal behaviour}

At $2260 \mathrm{~m}$, the cattle in each group behaved as usual and no abnormality was observed in both seasons. At $3250 \mathrm{~m}$, the animals looked good in the summer, except for an extreme hyperpnoea at higher Ta $\left(17 \cdot 0-23 \cdot 0^{\circ} \mathrm{C}\right)$ with sunshine. In the winter, however, the cattle appeared not to adapt to the cold $\left(0 \cdot 0--30 \cdot 0^{\circ} \mathrm{C}\right)$, being characterised by decreased grazing time, shivering, erect hair and bow back. At $4270 \mathrm{~m}$, the eating or grazing time and BW in the summer declined during the pre-measurement period, and the body temperature was lower $\left(37.4^{\circ} \mathrm{C}\right)$ than that at 2260 and $3250 \mathrm{~m}$ $\left(38.5^{\circ} \mathrm{C}\right)$. On this basis, the starvation lasted for only $4 \mathrm{~d}$ and the gas measurements were performed on days 3 and 4. In the winter at this altitude, the reduction of eating time and the loss of BW were greater than in the summer: two animals died during the adaptation period and three died $2 \mathrm{~d}$ after the commencement of starvation. The measurement was thus ended and no data were obtained.

\section{The heart rate, respiratory rate and rectal temperature}

Changes in the heart rate, respiratory rate and rectal temperature are shown in Fig. 1. All of the variables rapidly decreased in the $2 \mathrm{~d}$ after the starvation started, and became stable from day 5 . There was no difference between the values at 2260 and $3250 \mathrm{~m}$ in the winter; the values, except for the heart rate (similar at 2260 and $4270 \mathrm{~m}$ ), were higher at $3250 \mathrm{~m}$, and lower at $4270 \mathrm{~m}$, than those at $2260 \mathrm{~m}$ in the summer. No difference was observed between groups.

\section{Fasting heat production}

The recorded Ta during measurements in the summer at 2260, 3250 and $4270 \mathrm{~m}$ averaged 12.5 (range 5.0-26.0), $13 \cdot 2$ (range $8 \cdot 0-23 \cdot 0$ ) and $10 \cdot 0$ (range $4 \cdot 0-17 \cdot 0)^{\circ} \mathrm{C}$ respectively. The daily FHP pooled from the four measurements each day at these temperatures significantly increased with increase of altitude $(P<0 \cdot 01)$, except for the results from 2.0-year-old cattle from 3250 to $4270 \mathrm{~m}$ (Table 1). FHP, expressed as $\mathrm{kJ} / \mathrm{kg}$ metabolic $\mathrm{BW}$, was similar between the 2.0- and 3.0-year-old groups, but higher for the 1.0-year-old group.

The responses of FHP in the 2.0- and 3.0-year-old groups to altitude and solar radiation at the same Ta are shown in Table 2. At $2260 \mathrm{~m}$, FHP was not significantly affected by Ta and solar radiation, and only showed a small increasing tendency with increase of $\mathrm{Ta}$ with solar radiation and a small decreasing tendency without solar radiation. At 3250 and $4270 \mathrm{~m}, \mathrm{FHP}$ at any of the Ta ranging from 10.0 to $22 \cdot 0^{\circ} \mathrm{C}$ was significantly higher $(P<0.01)$ with solar radiation, and it significantly increased $(P<0 \cdot 01)$ with increase of $\mathrm{Ta}$ in the presence of solar radiation, whereas it decreased slightly with increase of Ta in the absence of solar radiation. At the same Ta, the magnitude of the FHP increase caused by increasing altitude was greater with solar radiation than without it.

The FHP measured in the winter is given in Table 3 . The mean Ta during measurements at 2260 and $3250 \mathrm{~m}$ were -4.6 and $-12.1^{\circ} \mathrm{C}$, ranging from -15.0 to $0.0^{\circ} \mathrm{C}$ and -30.0 to $-3 \cdot 0^{\circ} \mathrm{C}$ respectively. The daily FHP pooled from the five measurements under the natural temperature was higher at $3250 \mathrm{~m}$ than at $2260 \mathrm{~m}$.

The responses of FHP to altitude and winter wind at the same Ta in the 2.5- and 3.5-year-old groups are shown in 

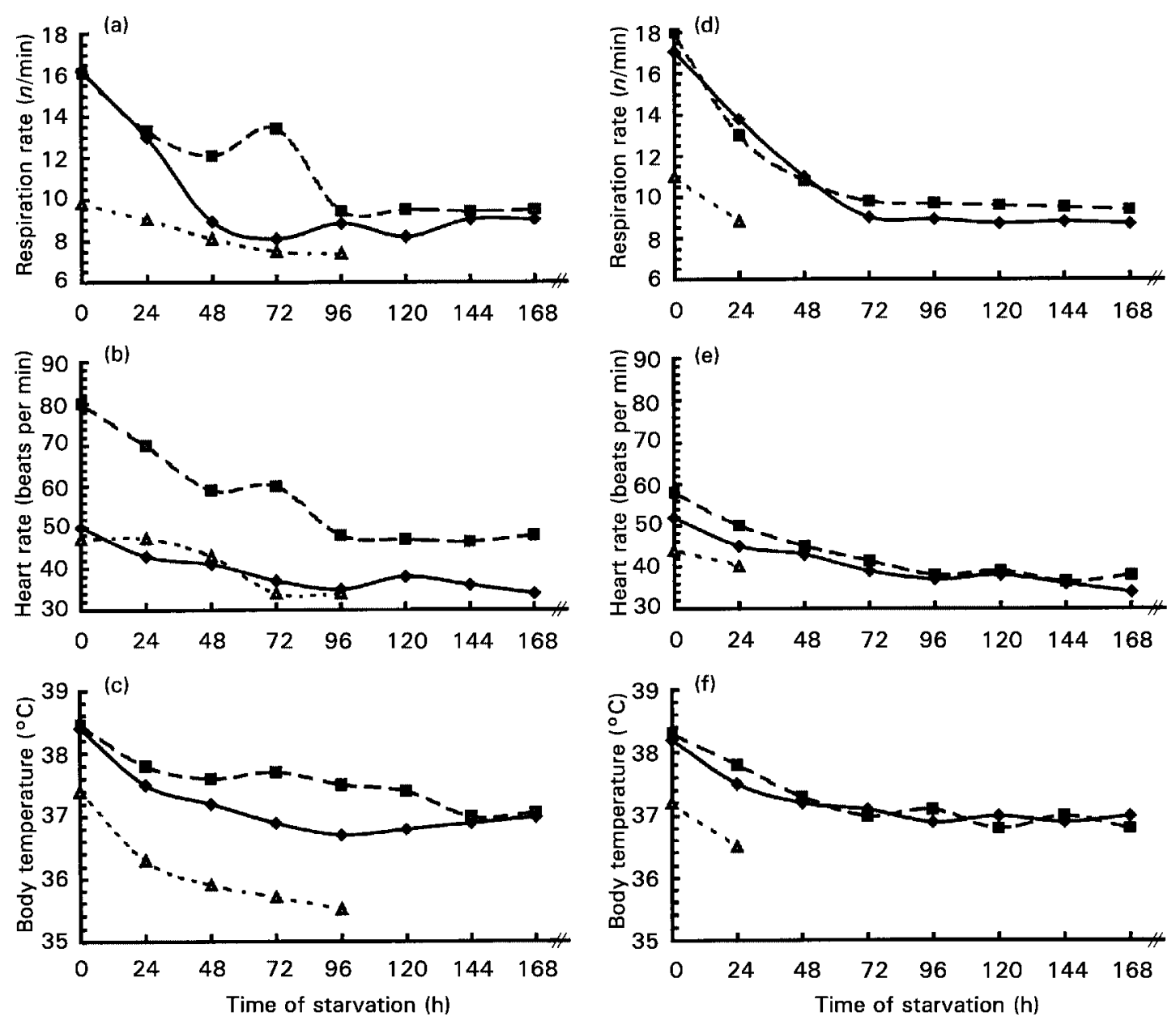

Fig. 1. Effect of altitude on respiratory rate, heart rate and body temperature in yellow cattle (Bos taurus) during

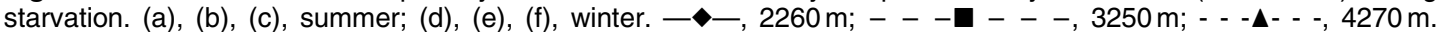
For details of procedures, see p. 400.

Table 4. Data collected with wind speed $<0.5 \mathrm{~m} / \mathrm{s}$ were considered as 'without wind' and the remaining were treated as 'with wind'. The wind speed in the 'with wind' group averaged on 2.5 and $5.2 \mathrm{~m} / \mathrm{s}$ at 2260 and $3250 \mathrm{~m}$ respectively. The FHP at the same Ta was slightly different between 2260 and $3250 \mathrm{~m}$ in the presence of wind, but similar in the absence of wind. At both altitudes, the FHP slightly increased with decrease of Ta.
A summary of FHP predicted from equations established with the measured data is presented in Table 5. The measured data at each altitude in a given season were subjected to the model: FHP $(\mathrm{kJ} / \mathrm{d})=\mathrm{a} \times \mathrm{BW}^{\mathrm{b}}$, using the least squares method. The established FHP in the summer and winter were: $870 \times \mathrm{BW}^{0.494}(n 12, r 0.792)$ and $1075 \times$ $\mathrm{BW}^{0.475}(n 11, r 0.837)$ at $2260 \mathrm{~m}, 801 \times \mathrm{BW}^{0.591}(n 12$, $r 0.876)$ and $764 \times \mathrm{BW}^{0.570}(n 12, r 0.867)$ at $3250 \mathrm{~m}$,

Table 1. Effect of altitude on daily fasting heat production $\left(\mathrm{kJ} / \mathrm{kg}\right.$ body weight ${ }^{0.75}$ ) of yellow cattle (Bos taurus) under natural ambient temperature in the summert‡

(Mean values for four animals per age group and standard errors for all values)

\begin{tabular}{lcccccc}
\hline Age (years) & BW $(\mathrm{kg}) \S$ & $2260 \mathrm{~m} \|$ & $3250 \mathrm{~m} \|$ & $4270 \mathrm{~m} \|$ & SE & Statistical significance of effect of altitude \\
\hline 1.0 & $65-85$ & $293^{\mathrm{a}}$ & $415^{\mathrm{b}}$ & $453^{\mathrm{c}}$ & 30 & $\star *$ \\
2.0 & $140-160$ & $251^{\mathrm{c}}$ & $354^{\mathrm{d}}$ & $360^{\mathrm{d}}$ & 22 & $* \star$ \\
3.0 & $180-200$ & $219^{\mathrm{c}}$ & $358^{\mathrm{d}}$ & & 19 & $* \star$ \\
\hline
\end{tabular}

a,b,c,d Mean values within a row or column with unlike superscript letters were significantly different $(P<0.05)$.

** $P<0.01$.

† For details of diets and procedures, see p. 400

$¥$ Values are the summation of four determinations each day and corrected into values under real standing-lying state.

$\S$ Fasted BW recorded during measurement.

$\| 2260 \mathrm{~m}, 5.0-26 \cdot 0^{\circ} \mathrm{C} ; 3250 \mathrm{~m}, 8 \cdot 0-23.0^{\circ} \mathrm{C} ; 4270 \mathrm{~m}, 4.0-17.0^{\circ} \mathrm{C}$. 
Table 2. Daily fasting heat production $\left(\mathrm{kJ} / \mathrm{kg}\right.$ body weight ${ }^{0.75}$ ) of yellow cattle (Bos taurus) measured in the summer at different ambient temperatures (Ta) with or without solar radiation†‡

(Mean values for cattle aged 2.0 and 3.0 years and standard errors for all values)

\begin{tabular}{|c|c|c|c|c|c|}
\hline $\mathrm{Ta}\left({ }^{\circ} \mathrm{C}\right)$ & $2260 \mathrm{~m} \S$ & $3250 \mathrm{~m} \S$ & $4270 \mathrm{~m} \S$ & SE & Statistical significance of effect of altitude \\
\hline \multicolumn{6}{|c|}{ With solar radiation } \\
\hline 10 & $230^{\text {af }}$ & $364^{b}$ & $377^{\mathrm{b}}$ & 19 & ** \\
\hline 14 & $226^{a}$ & $389^{\mathrm{bc}}$ & $393^{\mathrm{bc}}$ & 21 & ** \\
\hline 18 & $234^{\text {af }}$ & $406^{\mathrm{C}}$ & $423^{\mathrm{C}}$ & 26 & ** \\
\hline 20 & $251^{\text {af }}$ & $448^{d}$ & & 35 & ** \\
\hline 22 & $264^{f}$ & $502^{e}$ & & 32 & ** \\
\hline \multicolumn{6}{|c|}{ Without solar radiation } \\
\hline 10 & $259^{\text {af }}$ & $289^{\text {ag }}$ & $305^{\text {gh }}$ & 12 & ** \\
\hline 14 & $238^{\text {af }}$ & $276^{\mathrm{ag}}$ & $293^{g h}$ & 9 & $\star \star$ \\
\hline 18 & $234^{\text {af }}$ & $268^{a g}$ & & 17 & NS \\
\hline 20 & $226^{a}$ & $268^{g}$ & & 16 & $\star$ \\
\hline
\end{tabular}

$\mathrm{a}, \mathrm{b}, \mathrm{c}, \mathrm{d}, \mathrm{e}, \mathrm{f}, \mathrm{g}, \mathrm{h}$ Mean values within a row or column with unlike superscript letters were significantly different $(P<0.05)$. ${ }^{\star} P<0.05,{ }^{\star *} P<0.01$.

† For details of diets and procedures, see p. 400

$\ddagger$ Data were calculated from determinations at 09.00 and 15.00 hours in the standing state.

$\S 2260 \mathrm{~m}, n \geq 8 ; 3250 \mathrm{~m}, n \geq 8 ; 4270 \mathrm{~m}, n \geq 4$.

Table 3. Effect of altitude on daily fasting heat production $\left(\mathrm{kJ} / \mathrm{kg}\right.$ body weight $\left.{ }^{0.75}\right)$ of yellow cattle (Bos taurus) under natural ambient temperature in the wintertł

(Mean values for four animals per age group and standard errors for all values)

\begin{tabular}{lccccc}
\hline Age (years) & BW $(\mathrm{kg}) \S$ & $2260 \mathrm{~m} \|$ & $3250 \mathrm{~m} \|$ & SE & Statistical significance of effect of altitude \\
\hline 1.5 & $130-150$ & $277^{\mathrm{a}}$ & $313^{\mathrm{b}}$ & 23 & $*$ \\
2.5 & $170-190$ & $258^{\mathrm{a}}$ & $299^{\mathrm{b}}$ & 16 & $*$ \\
3.5 & $200-220$ & $251^{\mathrm{a}}$ & $294^{\mathrm{b}}$ & 31 & $*$
\end{tabular}

${ }^{a, b}$ Mean values within a column with unlike superscript letters were significantly different $(P<0.05)$.

${ }^{*} P<0.05$.

† For details of diets and procedures, see p. 400.

$¥$ Values are the summation of the five determinations each day and corrected into values under real standing-lying state.

$\S$ Fasted BW during measurement.

$\| 2260 \mathrm{~m},-15 \cdot 0-0.0^{\circ} \mathrm{C} ; 3250 \mathrm{~m},-30 \cdot 0--3 \cdot 0^{\circ} \mathrm{C}$.

and $2280 \times \mathrm{BW}^{0.384}$ (summer, $n 7, r 0.819$ ) at $4270 \mathrm{~m}$ respectively. Overall, FHP was greater with higher altitude in both seasons. FHP in the winter was higher at $2260 \mathrm{~m}$, but lower at $3250 \mathrm{~m}$ than those in the summer under the natural environment conditions. There were significant altitude and season interactions with FHP.

\section{RER}

RER were similar between groups and between seasons. The mean RER at 2260, 3250 and $4270 \mathrm{~m}$, from all groups and during both seasons (only summer values at $4270 \mathrm{~m}$ ), were $0.740,0.761$ and 0.555 respectively, showing a significant decrease from 2260 or 3250 to $4270 \mathrm{~m}$ $(P<0 \cdot 01)$.

\section{Standing time}

There was no difference in standing time between groups at all sites. The mean values at 2260, 3250 and $4270 \mathrm{~m}$ were $59.0,62.7$ and $42.2 \%$ in the summer respectively, and $63.4(2260 \mathrm{~m})$ and $56.3 \%(3250 \mathrm{~m})$ in the winter. The standing time was similar in the two seasons at 2260 and $3250 \mathrm{~m}$, but higher $(P<0 \cdot 05)$ at 2260 and $3250 \mathrm{~m}$ than at $4270 \mathrm{~m}$ in the summer. Further analysis showed that the summer standing time during the day was significantly higher $(P<0.01)$ with sunshine than without it at the same altitude.

\section{Discussion}

The aims of our present study were to determine the influences of environmental factors, particularly high altitude, on $\mathrm{O}_{2}$ consumption in large mammals. The study could have been carried out at a feeding level near maintenance energy requirement to avoid the death of young animals at $4270 \mathrm{~m}$. However, feeding level control is quite difficult on the Tibet plateau, particularly in grazing conditions. Furthermore, reduction of intake occurs at high altitude (Gill \& Pugh, 1964; Armellini et al. 1997). For these reasons, we starved the animals during measurements, to avoid feeding effects. The measured FHP is discussed partly using the BMR in human subjects, since both are obtained in the post-absorptive condition and may be considered as the minimal metabolic rate, although FHP is not the same as BMR. Results for $\mathrm{O}_{2}$ consumption or maintenance energy requirement, but not maximal $\mathrm{O}_{2}$ consumption or heat production, are also cited from literature in our discussion, because changes in these two variables parallels those of FHP or BMR (Blaxter, 1978; Haque et al. 1998; Mawson et al. 2000). 
Table 4. Daily fasting heat production $\left(\mathrm{kJ} / \mathrm{kg}\right.$ body weight $\left.{ }^{0.75}\right)$ of yellow cattle (Bos taurus) measured in the winter at different ambient temperature (Ta) with or without wind ${ }^{*} \ddagger$

(Mean values for cattle aged 2.5 and 3.5 years and standard errors for all values)

\begin{tabular}{lcccc}
\hline Ta $\left({ }^{\circ} \mathrm{C}\right)$ & $2260 \mathrm{~m} \S$ & $3250 \mathrm{~m} \S$ & SE & Statistical significance of effect of altitude \\
\hline With wind $\|$ & & & & \\
-15 & $280^{\mathrm{a}}$ & $303^{\mathrm{a}}$ & 23 & $\dagger$ \\
-10 & $268^{\mathrm{a}}$ & $291^{\mathrm{a}}$ & 16 & $\dagger$ \\
-5 & $255^{\mathrm{a}}$ & $278^{\mathrm{ab}}$ & 9 & $\dagger$ \\
\multicolumn{2}{l}{ Without windף } & & & $\mathrm{NS}$ \\
-15 & $276^{\mathrm{a}}$ & $273^{\mathrm{ab}}$ & 21 & $\mathrm{NS}$ \\
-10 & $263^{\mathrm{a}}$ & $265^{\mathrm{ab}}$ & 15 & $\mathrm{NS}$ \\
-5 & $253^{\mathrm{a}}$ & $244^{\mathrm{b}}$ & 12 & \\
\hline
\end{tabular}

\footnotetext{
${ }^{\mathrm{a}, \mathrm{b}}$ Mean values within a column with unlike superscript letters were significantly different $(P<0.05)$. $\dagger P<0 \cdot 10$.

${ }^{*}$ For details of diets and procedures, see p. 400.

$\ddagger$ Values were calculated from determinations in standing state, and those obtained at 04.00 hours were excluded.

Table 5. Effects of altitude and season on daily fasting heat production $\left(\mathrm{kJ} / \mathrm{kg}\right.$ body weight $\left.{ }^{0.75}\right)$ of yellow cattle (Bos taurus) under natural ambient temperature $\ddagger \S$

(Mean values for four animals per age group and standard errors for all values)

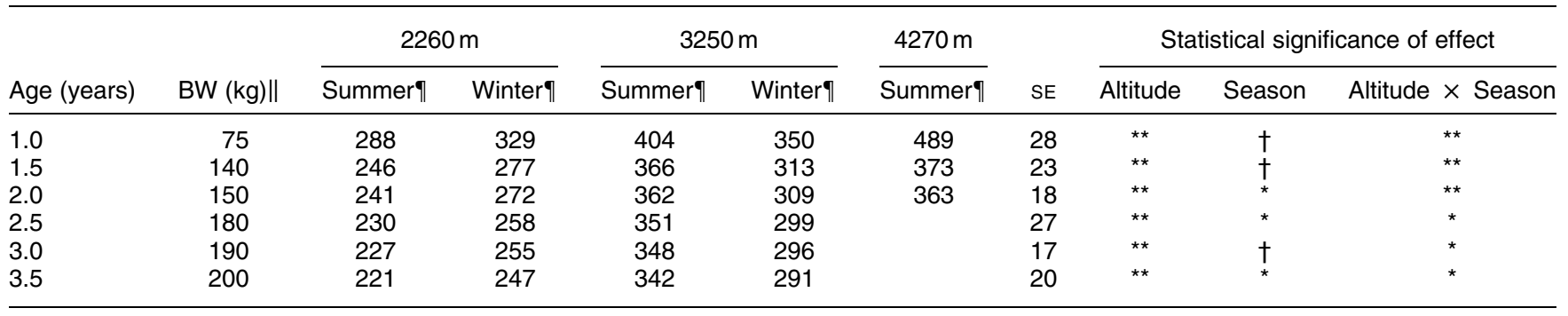

BW, body weight.

$\dagger P<0.10,{ }^{*} P<0.05,{ }^{* *} P<0.01$

$\ddagger$ For details of diets and procedures, see p. 400 .

$\S$ Mean values were predicted from equations based on values in Tables 1 and 3 , and statistical values were based on predicted individual values.

$\|$ Fasted BW.

9 $2260 \mathrm{~m}$ : summer values predicted from $870 \times \mathrm{BW}^{0.494}$ ( $n$ 12, $r$ 0.792), winter values predicted from $1075 \times \mathrm{BW}^{0.475}$ ( $n$ 11, $r 0.837$ ); $3250 \mathrm{~m}$ : summer values predicted from $801 \times \mathrm{BW}^{0.591}(n 12, r 0.876)$, winter values predicted from $764 \times \mathrm{BW}^{0.570}(n 12, r 0.867)$; $4270 \mathrm{~m}$ : summer values predicted from $2280 \times \mathrm{BW}^{0.384}$ $(n 7, r 0 \cdot 819)$.

\section{Effect of altitude on energy metabolism}

Many researchers have reported the effect of high altitude on BMR or $\mathrm{O}_{2}$ consumption in mammals (for review, see Gautier, 1996). Except for those obtained with small species, the published results indicate that the basal $\mathrm{O}_{2}$ consumption and FHP were either increased or not affected by high-altitude exposure (Armellini et al. 1997; Han et al. 2002). In the present study, increasing altitude at the same or similar Ta significantly increased FHP in the summer (Tables 1 and $2, P<0 \cdot 01$ ). These results agree well with previous studies, which revealed significantly elevated BMR or $\mathrm{O}_{2}$ consumption in sea-level residents exposed to high altitudes on Mt Bianco (Italy, $3800 \mathrm{~m}$; Kellogg et al. 1957) or the Jungfraujoch (Switzerland, $3454 \mathrm{~m}$; Klausen et al. 1968), in residents of Denver (CO, USA) living on Mt Evans (4310m; Grover, 1963), and in Sherpa and Caucasian mountaineers climbing up to the Himalayas (5800 m; Gill \& Pugh, 1964). In our present study, although the yellow cattle were collected from an area where the altitude ranges from 2000 to $2800 \mathrm{~m}$, FHP increased even when the altitude was increased from 2260 to $3250 \mathrm{~m}$. Similarly, Terzioglu \& Aykut (1954) recorded, at a relatively low altitude of $1850 \mathrm{~m}$, a significant increase in basal $\mathrm{O}_{2}$ consumption. In contrast, several researchers reported that the BMR in human subjects (Dempsey \& Forster, 1982; Mawson et al. 2000), and FHP (Blaxter, 1978; Haque et al. 1998; Han et al. 2002) and $\mathrm{O}_{2}$ consumption (not maximal $\mathrm{O}_{2}$ consumption) in fed conditions (Hemingway \& Nahas, 1952; Piiper et al. 1966; Forster et al. 1976; Blaxter, 1978; Bouverot et al. 1981; Forster et al. 1981; Haque et al. 1998) in various animal species, were not significantly affected during hypoxia. Inconsistancy between studies may be due to the adaptation level of animals or human subjects to high altitude (Zhuang et al. 1993; Haque et al. 1998; Han et al. 2002).

In the current study, although the yellow cattle used are found in areas with altitudes $<3000 \mathrm{~m}$, the FHP was increased by increasing altitude from 2260 to $3250 \mathrm{~m}$, or 
from 3250 to $4270 \mathrm{~m}$. In addition, the animals appeared not to adapt to high altitude, by showing reduced grazing or eating time at $4270 \mathrm{~m}$ in the summer, reduced grazing time, shivering, erect hair and bow back at $3250 \mathrm{~m}$ and even death in the winter at $4270 \mathrm{~m}$. In a twin study (Han et al. 2002), we measured, in the same conditions including feeding and length of starvation, the FHP in the yak (Bos grunniens or Poephagus grunniens), a large mammal native to areas of high altitude ranging from 3000 to $6000 \mathrm{~m}$ in the Tibet plateau. We found that at similar Ta, increase in altitude from 2260 to $3250 \mathrm{~m}$ or from 3250 to $4270 \mathrm{~m}$ had no any effect on the FHP in this species in the winter or summer, and that the yaks did not show any change in their behaviour at high altitude. Similarly, FHP and maintenance energy requirement measured at $2400 \mathrm{~m}$ in goats living above $3500 \mathrm{~m}$ in the Himalayan range were similar to those in goats found in the plains of India (Haque et al. 1998). These studies, especially our studies with cattle and yaks (present study; Han et al. 2002), suggest that the response of FHP is dependent on the extent of adaptation of mammals to high altitude, and may thus explain the difference between the results of studies including the current findings.

Many studies have demonstrated that the increase in BMR in human subjects at high altitudes is a transient phenomenon that may disappear within a few weeks of high-altitude exposure (Kellogg et al. 1957; Hannon et al. 1969, 1976; Hannon \& Sudman, 1973; Hannon, 1978; Mawson et al. 2000). However, Butterfield et al. (1992) found the BMR in seven men during $21 \mathrm{~d}$ of high-altitude exposure to increase by $27 \%$ after $2 \mathrm{~d}$ and then decrease, reaching a plateau at $17 \%$. In the present study, the summer FHP at the same Ta in most groups was significantly higher at a higher altitude, even though the cattle were at the experimental sites at least for 3 months before measurements. This implies that the transient increase of BMR in animals exposed to high altitude may last for 3 months. The FHP at $3250 \mathrm{~m}$ in the winter, however, was similar to that measured at $2260 \mathrm{~m}$ at the same Ta without wind (Table 4). It might be that the elevated FHP observed in the summer declined, due to gradual adaptation to high altitude, to the values at $2260 \mathrm{~m}$ after 3 months, since after the summer measurements the cattle stayed at $3250 \mathrm{~m}$ until the winter measurements in December and January.

Recently, Mawson et al. (2000) divided their subjects into groups that were 'fit' and 'less fit' for high altitudes according to the maximum $\mathrm{O}_{2}$ consumption at sea level. Their results indicated that the elevated BMR fell to sealevel values in the fit women, whereas it remained elevated by $10 \%$ above sea-level values in the less-fit women. This implies that the fit women were able to adapt better metabolically to the stress of altitude than less-fit women were. Perhaps there is also a difference in the fitness level between different species, and the cattle used here might be less fit for high altitude, and this may have maintained the elevated FHP after $90 \mathrm{~d}$ of high-altitude exposure.

In the present study, the RER significantly decreased $(P<0.01)$ with increase of altitude from 2260 or 3250 to $4272 \mathrm{~m}$. A similar decrease in RER has been reported in the yak when the altitude was increased from 2260 to $3250 \mathrm{~m}$ or from 3250 to $4270 \mathrm{~m}$ (Han et al. 2002). In mammals, there are a number of factors that could explain RER $<0 \cdot 70$, including methodological errors, ventilatory effects and metabolites such as ketone bodies whose RER may be zero (Schutz \& Ravussin, 1980). In our present study, technical problems should be excluded, because the methods used were the same for all altitudes. It is possible that the ketone bodies produced during starvation were not completely oxidized at $4270 \mathrm{~m}$. It is also likely that the low RER is a physiological phenomenon related to hypoventilation, since lower arterial $P_{\mathrm{O}_{2}}$ and higher $P_{\mathrm{CO}_{2}}$ have been reported in lifelong highaltitude residents (Chiodi, 1957; Lahiri, 1968).

The heart rate and rectal temperature in the summer were higher in animals at $3250 \mathrm{~m}$ than at $4270 \mathrm{~m}$. During the measurement at $3250 \mathrm{~m}$, but not at $4270 \mathrm{~m}$, the weather was always bright and sunny, and hyperpnoea was observed at $3250 \mathrm{~m}$ in the presence of solar radiation. Thus, we suppose that the higher values at $3250 \mathrm{~m}$ were probably caused by stronger solar radiation there, though the intensity of the solar radiation was not measured and there is no information on solar radiation at each site. This explanation may be supported by the winter measurements, which showed no differences in the variables between altitudes. In cattle, the stimulating effect of solar radiation on rectal temperature and respiratory rate has been reported (Yamamoto et al. 1994; Brosh et al. 1998). The rectal temperature measured in four animals at the beginning of starvation in the winter at $4270 \mathrm{~m}$ was approximately $37.0^{\circ} \mathrm{C}$; the death of the five younger cattle was, therefore, probably not due to the exhaustion of body energy stores, but to the drop of body temperature and metabolic rate.

\section{Effect of ambient temperature on the fasting metabolism}

It is recognised that metabolic rate increases when animals are subjected to chronic cold exposure, and that the magnitude of the increase is apparently related to the extent of cold stress (National Research Council, 1981). In the present study, the FHP at $2260 \mathrm{~m}$ was significantly greater $(P<0.05)$ in the winter than in the summer for all groups (Table 5). This is in accordance with studies in growing (Webster, 1970) and adult (Young, 1975) cattle, which demonstrate that resting metabolic rate, or fasting metabolism, is increased from 30 to $40 \%$ as a result of physiological acclimation to several weeks of cold exposure.

The FHP at $3250 \mathrm{~m}$, however, was higher in the summer than in the winter (Table 5). This is similar to our previous results with yaks in the same conditions (Han et al. 1992, 2002), but quite different from any other study at a similar air temperature. This may be mainly due to the effect of solar radiation in the summer, because significantly increased FHP (Table 2, $P<0 \cdot 01$ ), heart rate and respiration rate at this experimental site were measured at $\mathrm{Ta}$ ranging from $10 \cdot 0$ to $23.0^{\circ} \mathrm{C}$ and extreme hyperpnoea were observed at $\mathrm{Ta}>17 \cdot 0^{\circ} \mathrm{C}$ when there was sunshine. These results suggest that at $3250 \mathrm{~m}$ the solar radiation has a greater effect than low Ta does, and this resulted in higher FHP in the summer.

As discussed earlier, the elevated FHP in the summer probably declined because of gradual adaptation to the 
altitude in the later months of exposure at $3250 \mathrm{~m}$. This could also help to explain the lower FHP in the winter. Another possibility may be that the lower FHP in the winter is a result of altitude-temperature interaction, since hypometabolic responses have been reported to be greater at lower $\mathrm{Ta}$ than at higher Ta during hypoxia in mammals (Gautier \& Bonora, 1992; Saiki et al. 1994; Han et al. 2002) and non-mammals (Hou \& Huang, 1999; Staples et al. 2000). In our present study, the high altitude probably reduced FHP in cold environment $\left(0 \cdot 0--30 \cdot 0^{\circ} \mathrm{C}\right)$, which concealed the cold effect as observed at $2260 \mathrm{~m}$.

Further analysis of the results obtained both in the summer and winter indicated that FHP was minimal and similar at environmental temperatures ranging from 14.0 to $20.0^{\circ} \mathrm{C}$ at 2260 and $3250 \mathrm{~m}$ in the absence of sunshine. The lower critical $\mathrm{Ta}\left(14.0^{\circ} \mathrm{C}\right)$ seems low as compared with $18.0^{\circ} \mathrm{C}$ observed by Blaxter \& Wainman (1961) in fasted cattle. This may be either a result of adaptation of the animal to lower Ta at 2000 to $3000 \mathrm{~m}$, or a breed effect: the thermoneutral zone in cattle differs greatly with breed, mainly due to the different environments in which they live (Blaxter \& Wainman, 1961; Han et al. 1992).

\section{Effects of solar radiation and wind on metabolic rate}

Several researchers have documented the effect of solar radiation on energy metabolism in ruminant animals kept in a hot environment at or near sea level; the results from these studies, however, vary with species or breed. In heifers kept at $18 \cdot 0,24 \cdot 0,28 \cdot 0$ or $30 \cdot 0^{\circ} \mathrm{C}$, the solar radiation did not affect heat production and heart rate, despite the heat load induced by the radiation and the significantly increased respiratory rate and rectal temperature (Yamamoto et al. 1994; Brosh et al. 1998). In contrast, in goats exposed to solar radiation in the summer $\left(30 \cdot 0^{\circ} \mathrm{C}\right), \mathrm{O}_{2}$ consumption was $15 \%$ lower than those in radiation-protected goats (Brosh, 1985, cited by Brosh et al. 1998); however, in buffalo in a hot environment $\left(39.0^{\circ} \mathrm{C}\right.$ at about 14.00 hours) in the summer, the heart rate, which is positively related to heat production (Brosh et al. 1998), increased during exposure to solar radiation (Mullick, 1960; Chaiyabutr et al. 1990). In the present study, the summer radiation at $2260 \mathrm{~m}$ did not affect $\mathrm{FHP}$ at $18.0^{\circ} \mathrm{C}$, but slightly reduced it at $\mathrm{Ta}<$ $14 \cdot 0^{\circ} \mathrm{C}$ and slightly elevated it at $\mathrm{Ta}>20^{\circ} \mathrm{C}$ (Table 2). Although these changes were not statistically different, they may suggest that Ta could be a crucial variable in determining the effects of solar radiation on metabolic rate: the radiation could reduce heat production at low $\mathrm{Ta}$ and increase it at high $\mathrm{Ta}$. The response at $>18 \cdot 0^{\circ} \mathrm{C}$ was similar to that in buffalo, but is not similar to those in goats and heifers. It is likely the changes in goats, yellow cattle and buffalo are particular features of each species.

The FHP at 3250 and $4270 \mathrm{~m}$ was significantly higher $(P<0.01)$ in the presence of sunshine at any of the air temperatures from $10 \cdot 0$ to $20 \cdot 0^{\circ} \mathrm{C}$. Furthermore, FHP increased lineally with increase of $\mathrm{Ta}$ in the presence of sunshine, whereas it tended to decrease with increase of $\mathrm{Ta}$ in the absence of sunshine (Table 2). These results neither agree with the results at $2260 \mathrm{~m}$ in this present study nor with the results with goat and cattle in other studies
(Brosh, 1985, cited by Brosh et al. 1998; Yamamoto et al. 1994). A reasonable explanation may be that the cattle experienced very large heat loads from solar radiation at 3250 and $4270 \mathrm{~m}$, and that a very large proportion of the intercepted radiation was transferred to the insulating coat and skin of the animals. As a result, the temperature in the insulating coat and skin of the animals exceeded the higher critical temperature, which resulted in the increase of heat production. The different response of FHP to solar radiation between 2260 and 3250 or $4270 \mathrm{~m}$ suggests that altitude is another crucial variable in determining the metabolic response to solar radiation.

Wind may affect energy expenditure both in hot and cold environments, particularly in animals with a thin coat of hair. In our present study, FHP in the winter at $3250 \mathrm{~m}$ with natural wind velocity averaging on $5.2 \mathrm{~m} / \mathrm{s}$ was approximately $10 \%$ higher with wind than without it. This is consistent with studies in pigs (Close \& Heavens, 1981), white-tailed jackrabbits (Lepus townsendi; Rogowitz \& Gessaman, 1990) and human subjects (Mäkinen et al. 2000 ) in cold environments. However, FHP at $2260 \mathrm{~m}$ in the same season was not affected by mean wind speeds of $2.5 \mathrm{~m} / \mathrm{s}$. The difference between altitudes may be attributed to the different wind speed, since low wind velocity has no effect on $\mathrm{O}_{2}$ consumption compared with high wind velocity (Mäkinen et al. 2000).

\section{Conclusion}

In summary, the present results demonstrate that increasing altitude, at similar Ta, elevates the FHP in yellow cattle in the summer but not in the winter, and that the summer solar radiation and the winter wind at high altitude significantly increase metabolic rate at the same Ta. The results also suggest that the effects of Ta on metabolic rate vary with solar radiation and the effects of solar radiation depend on the altitude and the environmental temperature. The results provide additional information of the energy metabolism in large mammals at high altitude and harsh environment.

\section{Acknowledgements}

The authors would like to thank Yue-Ping Zhao, Xiao-Wei Zhang, Gui-Fang Qiu, Wei-Jun Cai, Yu-Zhe Feng, Qing-Lin $\mathrm{Xu}$ and Cheng-Ying $\mathrm{Hu}$ for their assistance with the experiments.

\section{References}

Armellini F, Zamboni M, Robbi R, Todesco T, Bissoli L, Mino A, Angelini G, Micciolo R \& Bosello O (1997) The effects of high altitude trekking on body composition and resting metabolic rate. Hormone and Metabolism Research 29, 458-461.

Blaxter KL (1978) The effect of stimulated altitude on the heat increment of feed in sheep. British Journal of Nutrition 39, 659-661.

Blaxter KL \& Wainman FW (1961) Environmental temperature and the energy metabolism and heat emission of steers. Journal of Agricultural Science, Cambridge 56, 81-90.

Bouverot P, Collin R, Favier R, Flandrois R \& Sebert P (1981) Carotid chemoreceptor function in ventilatory and circulatory 
$\mathrm{O}_{2}$ convection of exercising dogs at low and high altitude. Respiratory Physiology 43, 147-167.

Brosh A, Aharoni Y, Degen AA, Wright D \& Young BA (1998) Effects of solar radiation, dietary energy, and time of feeding on thermoregulatory responses and energy balance in cattle in a hot environment. Journal of Animal Science 76, 2671-2677.

Brouwer E (1965) Report of sub-committee on constants and factors. In Energy Metabolism. European Association of Animal Production Publication no. 11, pp. 441 [KL Blaxter, editor]. London: Academic Press.

Butterfield GE, Gates J, Fleming S, Brooks GA, Sutton JR \& Reeves JT (1992) Increased energy intake minimizes weight loss in men at high altitude. Journal of Applied Physiology 72, $1741-1748$.

Chaiyabutr N, Buranakarl C, Loypetjra P \& Chanpongsang S (1990) Effects of prolonged exposure to the sun on body water turnover and volume of the blood in swamp buffaloes. Asian-Australian Journal of Animal Science 3, 47-52.

Chiodi H (1957) Respiratory adaptations to chronic high altitude hypoxia. Journal of Applied Physiology 10, 81-87.

Close WH \& Heavens RP (1981) The effects of ambient temperature and air movement on heat loss from the pig. Animal Production 32, 75-84.

Dempsey JA \& Forster HV (1982) Mediation of ventilatory adaptations. Physiological Review 62, 262-346.

Forster HV, Bisgard GE \& Klein JP (1981) Effect of peripheral chemoreceptor denervation on acclimatization of goats during hypoxia. Journal of Applied Physiology 50, 392-398.

Forster HV, Bisgard GE, Rasmussen B, Orr JA, Buss DD \& Manohar M (1976) Ventilatory control in peripheral chemoreceptor denervated ponies during chronic hypoxemia. Journal of Applied Physiology 41, 878-885.

Gautier H (1996) Interactions among metabolic rate, hypoxia, and control of breathing. Journal of Applied Physiology 81, 521 -527.

Gautier H \& Bonora M (1992) Ventilatory and metabolic responses to cold and hypoxia in intact and carotid body-denervated rats. Journal of Applied Physiology 73, 847-854.

Gill MB \& Pugh LGC (1964) Basal metabolism and respiration in men living at $5800 \mathrm{~m}(19,000 \mathrm{ft})$. Journal of Applied Physiology 19, 949-954.

Grover RF (1963) Basal oxygen uptake of man at high altitude. Journal of Applied Physiology 18, 909-912.

Han XT (1990) Factors affecting fasting metabolism in ruminants. Qinghai Journal of Animal and Veterinary Sciences 20, 30-33.

Han XT, Liu SJ, Bi XC, Wang WB, Xie AY \& Hu LH (1992) The thermoneutrality zone and the regularity of heat production beyond the zone in fasted growing yaks. Qinghai Journal of Animal and Veterinary Sciences 22, 18-20.

Han X-T, Xie A-Y, Bi X-C, Liu S-J \& Hu L-H (2002) Effects of high altitude and season on fasting heat production in the yak Bos grunniens or Poephagus grunniens. British Journal of Nutrition 88, 189-197.

Hannon JP (1978) Comparative altitude adaptability of men and women. In Environmental Stress: Individual Human Adaptations, pp. 335-350 [LJ Folinsbee, JA Wagner, JF Borgia, BL Drinkwater, JA Gliner and JF Bedi, editors]. New York: Academic Press.

Hannon JP, Klain GJ, Sudman DM \& Sulivan FJ (1976) Nutritional aspects of high altitude exposure in women. American Journal of Clinical Nutrition 29, 604-613.

Hannon JP, Shields JL \& Harris CW (1969) Anthropometric changes associated with high altitude acclimatization in women. American Journal of Physiological Anthropology 31, 77-84.

Hannon JP \& Sudman DM (1973) Basal metabolic and cardiovascular function of women during altitude acclimatization. Journal of Applied Physiology 34, 471-477.
Haque N, Murarilal MY, Khan MY, Biswas JC \& Singh P (1998) Metabolizable energy requirements for maintenance of pashmina producing Cheghu goats. Small Ruminant Research 27, $41-45$.

Hemingway A \& Nahas GG (1952) Effect of varying degrees of hypoxia on temperature regulation. American Journal of Physiology 170, 426-433.

Hou PC \& Huang SP (1999) Metabolic and ventilatory responses to hypoxia in two altitudinal populations of the toad, Bufo bankorensis. Comparative Biochemistry and Physiology 124A, 413-421.

Kellogg RH, Pace N, Archibald ER \& Vaughan BE (1957) Respiratory response to inspired $\mathrm{CO}_{2}$ during acclimatization to an altitude of 12,470 feet. Journal of Applied Physiology 11, 665-671.

Klausen K, Rasmussen B, Gjellerod H, Madsen H \& Peterson E (1968) Circulation, metabolism and ventilation during prolonged exposure to carbon monoxide and to high altitude. Scandinavian Journal of Laboratory Investigation 103, 26-38.

Lahiri S (1968) Alveolar gas pressures in man with life-time hypoxia. Respiratory Physiology 4, 373-386.

Mäkinen T, Gavhed D, Holmér I \& Rintamäki H (2000) Thermal responses to cold wind of thermoneutral and cooled subjects. European Journal of Applied Physiology 81, 397-402.

Mawson JT, Braun B, Rock PB, Moore LG, Mazzeo R \& Butterfield GE (2000) Women at altitude: energy requirement at $4300 \mathrm{~m}$. Journal of Applied Physiology 88, 272-281.

Mullick DN (1960) Effect of humidity and exposure to sun on the pulse rate, respiration rate, rectal temperature and haemoglobin level in different sexes of cattle and buffalo. Journal of Agricultural Science, Cambridge 54, 391-394.

National Research Council (1981) Effect of Environments on Nutrient Requirements of Domestic Animals. Washington, DC: National Academy Press.

National Research Council (1984) Nutrient Requirements of Beef Cattle. Washington, DC: National Academy Press.

Piiper J, Cerretelli P, Cuttica F \& Mangili F (1966) Energy metabolism and circulation in dogs exercising in hypoxia. Journal of Applied Physiology 21, 1143-1149.

Rogowitz GL \& Gessaman JA (1990) Influence of air temperature, wind, and irradiance on metabolism of white-tailed jackrabbits. Journal of Thermal Biology 15, 125-131.

Saiki C, Matsuoka T \& Mortola JP (1994) Metabolic-ventilatory interaction in conscious rats: effect of hypoxia and ambient temperature. Journal of Applied Physiology 76, 1594-1599.

Schutz Y \& Ravussin E (1980) Respiratory quotients lower than 0.70 in ketogenic diets. American Journal of Clinical Nutrition 33, 1317-1319.

Staples JF, Hershkowitz JJ \& Boutilier RG (2000) Effects of ambient $\mathrm{PO}_{2}$ and temperature on oxygen uptake in Nautilus pompilius. Journal of Comparative Physiology 170B, 231-236.

Terzioglu M \& Aykut R (1954) Variations in basal metabolic rate at $1.85 \mathrm{~km}$ altitude. Journal of Applied Physiology 7, 329-332.

Webster AJF (1970) Direct effects of cold weather on the energetic efficiency of beef production in different regions of Canada. Canadian Journal of Animal Science 50, 563-573.

Yamamoto S, Young BA, Purwanto BP, Nakamasu F \& Matsumoto $T$ (1994) Effect of solar radiation on the heat load of dairy heifers. Australian Journal of Agricultural Research 45, 1741-1749.

Young BA (1975) Effects of winter acclimatization on resting metabolism of beef cows. Canadian Journal of Animal Science $\mathbf{5 5}, 619-625$

Zhuang JG, Broma T, Sun SF, Janes C, McCullough RE, McCullough RG, Cymerman A, Huang SY, Reeves JT \& Moore LG (1993) Hypoxic ventilatory responsiveness in Tibetan compared with Han residents of $3658 \mathrm{~m}$. Journal of Applied Physiology 74, 303-311. 